SCientia Marina 70 (2)

June 2006, 219-226, Barcelona (Spain)

ISSN: 0214-8358

\title{
Understanding coral reefs as complex systems: degradation and prospects for recovery
}

\author{
RAYMOND T. DIZON ${ }^{1,2}$ and HELEN T. YAP ${ }^{1}$ \\ ${ }^{1}$ The Marine Science Institute, University of the Philippines, Diliman, 1101 Quezon City, Philippines. \\ E-mail: rtd@upmsi.ph \\ ${ }^{2}$ Institut de Ciencia i Tecnologia Ambientals, Universitat Autònoma de Barcelona, 08193 Bellaterra, Barcelona, Spain.
}

\begin{abstract}
SUMMARY: The present century is witness to unprecedented levels of coral reef degradation worldwide. Current understanding based on traditional ideas is unlikely to capture adequately the dynamics of phenomena accompanying this trend. In this regard, the ideas of complexity are reviewed. Some applications to coral reefs as complex systems have already been discussed in the literature although further progress is warranted as the search for new and more effective management tools continues, and the direction towards more holistic, integrative and large scale approaches gains wider acceptance. We distinguish between the concepts of robustness and resilience in the face of disturbance, highlight the various mechanisms that foster these stability properties and provide some coral reef examples. We identify some of the driving forces behind succession that are critical for community assembly and possible reef recovery. Finally, we consider how self-organization arises out of apparently random and chaotic processes and interactions to exhibit certain regularities and patterns especially when moving up on the scale of space and/or time.
\end{abstract}

Keywords: complexity, complex system, resilience, robustness, self-organization, scale.

RESUMEN: ARRECIFES DE CORAL COMO SISTEMAS COMPLEJOS: DEGRADACIÓN Y PERSPECTIVAS DE RECUPERACIÓN . - El presente siglo es testigo de niveles de degradación sin precedentes de los arrecifes de coral. El conocimiento previo basado en estudios tradicionales no es capaz de entender la dinámica de esta tendencia de degradación. En este contexto, las ideas sobre la complejidad de los arrecifes se revisa en este trabajo. Algunas aproximaciones sobre la complejidad de los arrecifes ya han sido mencionados en la literatura, pero se necesita progresar más y ser más efectivos en la línea de enfoques más holísticos, integrativos y de mayor escala que son, al mismo tiempo, los más aceptados actualmente. En el trabajo distinguimos conceptos de robustez y de resilencia dentro del marco de las perturbaciones, hacemos énfasiz en los mecanismos que confieren propiedad de estabilidad y planteamos ejemplos en los arrecifes de coral. Identificamos algunas fuerzas que gobiernan aspectos críticos para los arrecifes como es la sucesión ecológica y la posible recuperación de los mismos. Finalmente, consideramos cómo los procesos de auto-organización surgen de procesos aparentemente caóticos o al azar y de interacciones que permiten mostrar ciertas regularidades y pautas, especialmente cuando se aumenta la escala espacio temporal de observación.

Palabras clave: complejidad, sistema complejo, resiliencia, robustez, auto-organización, escala.

\section{INTRODUCTION}

The complexity theory as developed at the present time has gained its major strengths from fields such as non-linear Physics and studies on modern dynamical systems (Parrott, 2002). One of the important pioneers who has incorporated concepts from complexity theory into ecological thinking is C.S. Holling $(1973,2001)$, who focuses on terrestrial habitats. With respect to coral reefs, Bradbury $(1977,1996)$ has helped to elaborate how the science of complexity might underpin research at the ecosystem level, though his treatment of the subject is different from that in this paper. Hatcher (1984, 
1997) has carried the field further by describing specific features and processes in coral reefs that might be amenable to complex systems analysis. Folke and co-workers (Nyström et al., 2000; Scheffer et al., 2001; Hughes et al., 2003; Bellwood et al., 2004) invoke concepts such as resilience and "ecological memory" as important components of efforts to ameliorate the effects of environmental impacts, or to aid in coral reef recovery from perturbation. In terms of quantitative analysis, the work of Johnson (Preece and Johnson, 1993) demonstrates how tools such as cellular automata modelling can help explain how certain spatial patterns arise.

In this paper, we suggest that the view of coral reefs as complex systems is the appropriate one, and can serve as a basis for quantitative or experimental research to delve deeper into their dynamics. From this perspective, their assembly as natural communities, their responses to perturbation, and their recovery (or lack thereof) from environmental damage can be better explained. It is on this basis that attempts at management or restoration can be designed more effectively.

A suggested definition of a complex system is "a network of many components whose aggregate behaviour is both due to, and gives rise to, multiplescale structural and dynamical patterns which are not inferable from a system description that spans only a narrow window of resolution" (Parrott, 2002). In this paper, we select for discussion a subset of the ideas from the complexity theory that present themselves as eminently applicable in the study of coral reef ecosystems. These are the concepts of resilience and robustness (familiar from the literature on terrestrial ecology), community assembly, and the question of scale.

The present century is witness to unprecedented levels of coral reef degradation worldwide. A key question now is the ability of coral reefs to recover from these stresses (Nyström et al., 2000). In fact, the more correct question to pose, given the different kinds, intensity, duration, frequency and spatial scale of disturbances, is how are coral reefs changing and, in given situations where severe damage has occurred, can they recover at all? If they do recover, how long will it take, what development pathways will they follow, and can these be predicted? If they don't recover, what type of community can we expect to emerge?

Answers lie in understanding the nature of the disturbance and the underlying process(es) it affects or alters, the stability property of a particular system and the existence of alternative or multiple stable states or attractors (May, 1977; Knowlton, 1992; Haefner, 1996). Coral reefs, like other ecosystems, are always changing. These changes are brought about by internal (in the absence of disturbance) as well as external (as they are open systems) dynamics that occur gradually (continuous) or abruptly (sudden). The inherent resilience and robustness of coral reefs have contributed to their persistence, stability and existence for millions of years. These two concepts, although fundamentally different, tend to be combined and considered as "resilience" in the coral reef literature (McClanahan et al., 2002; Hughes et al., 2003; Bellwood et al., 2004). We discuss and distinguish between them in detail in the following sections.

\section{ROBUSTNESS}

There are many definitions for robustness but the one we employ here is based on the complex systems theory as widely developed by the Santa Fe Institute (Jen, 2001). Robustness is the degree to which a system can withstand or tolerate stress, perturbations or variations in its internal structure or external environment without malfunctioning (Jen, 2001). It is closely related to the concept of ecological resilience (Holling, 1996) and is also similar to resistance (Pimm, 1991) since it involves maintaining the status quo in the face of external forces. The existing state is by and large maintained with modifications taking place at different levels. This is achieved by having various alternate pathways or abilities to switch among multiple strategic options (Jen, 2001). However, unlike the case of resistance where a system simply endures stress and preserves the original configuration, robust systems are flexible and respond by allowing for adjustments to take place in order to adapt and evolve with the changing environment. Robust systems have their limitations and break down when certain thresholds or critical points are exceeded.

Two considerations are worth noting here. First, these thresholds, which are boundaries that if crossed in one direction cannot be easily reversed (Knowlton, 1992), are difficult to detect and have no warning signs (Scheffer et al., 2001). Difficulties arise in recognizing where to draw the line and recognize a threshold breach. Within a state there are continuous and sometimes large variations in 
species composition. What is the limit to the magnitude of differences we are to admit as mere natural variations within the formation of an existing state? And do these differences represent truly uniquely different stable communities or are we observing the system at an incorrect temporal and spatial scale? Researchers should consequently define shifts across a boundary or threshold based on changes in the integrity of the system's primary ecological processes and not just species compositions.

Second, there are various mechanisms that complex systems use to prevent or minimize failure and they include the following (Kitano, 2001):

1. redundancy

2. modularity

3. feedback

4. evolvability

Some of these principles have already been (or can be) incorporated in coral reef studies. Functional redundancy involves the compensation of a lost or damaged component by another one with a similar or overlapping function. Equivalent components occur in the same subsystem, but they differ in their tolerance to environmental conditions. A recent paper on coral reefs describes functional groups composed of species performing particular functions that may help the system absorb shocks (Bellwood et al., 2004). As a result of this functional redundancy the properties of the ecosystem are relatively insensitive to a certain degree to fluctuations in component species (O'Neill et al., 1986). For example, in the case of algae replacing corals where conditions change from oligotrophic to eutrophic, certain functions such as primary production are still preserved. This feature is also known as "degeneracy" which involves totally or structurally different components performing similar functions (Solé et al., 2003). In another example, the loss of herbivory as a function that had previously been performed by fish to control macroalgal abundance was compensated for by a certain species of sea urchin which became the principal grazer in shallow Caribbean reefs (McClanahan et al., 2002). Redundancy thus emerges from the interactions of species (Peterson et al., 1998).

Symbiotic associations are interactions that help organisms increase their tolerances to certain environmental conditions. Some researchers believe that corals are able to create tolerable conditions for themselves despite environmental stress such as a rise in temperature (Buddemeier and Fautin, 1993).
They do this by bleaching which may involve changes in the community structure of the zooxanthellae that they harbour (Baker, 2001). It is hypothesized that this compensatory change in algal symbiont communities will lead to a better suited partnership between algae and coral under the new environmental conditions. However, evidence for this is still debatable since bleached corals are followed by poor performance, and bleaching may be viewed as an ecological gamble that sacrifices short term benefits for the long term advantage (Baker, 2001). Perhaps it is crucial for corals to be able to switch from an autotrophic to heterotrophic mode of feeding, at least for short periods of time, without the algae if they are to survive.

Modular design ensures that damage in one part of the system does not spread to the entire system and allows reconfigurations throughout the evolutionary process (Kitano, 2001) as well as flexibility and variety in function. This can apply to reefs which are known to exhibit patchiness in their distribution. It is likely that spatial heterogeneity has the potential to minimize or buffer the spreading or cascading effects of perturbations such as invasions of undesirable organisms or disease.

However, the highly optimized tolerance (HOT) theory attempts to demonstrate that complex systems show robustness against common or anticipated perturbations but fragility against unusual ones (Carlson and Doyle, 2002). Barriers emerge and trade-offs between robustness and efficiency exist. Systems characterized by high production and increased efficiencies with reduced redundancies (i.e. low diversity) may be at a higher risk. For example, individual corals are believed to exhibit an inverse relationship between the rapid linear extension rate and skeletal density (McClanahan et al., 2002). Rapid linear extension implies an advantage in the occupation of available space. This would result in a monopoly of space by relatively few species with high colony extension rates. But this may reflect a compromise that corals must make in order to allocate energy optimally since reduced skeletal density means less resistance to breakage. Consequently, low diversity reefs containing fragile colonies are more susceptible to damage by catastrophic disturbances such as hurricanes which occur rarely but unpredictably.

There are many kinds of feedback that exist and operate on a reef in a wide range of scales and which may act simultaneously. The interactions between 
marine ecosystems and the physical climate system as exemplified by biogeochemical cycles are one example. Understanding them involves researching the different rates of materials delivered, retained, accumulated, recycled and removed from the system (Hatcher, 1997). Other forms of feedback include factors such as disturbance regimes, trophic interactions or food web architecture that may reinforce certain structures and functions while inducing change in others (Dent et al., 2002). All play a crucial role whether top-down (limited by predators or pathogens) or bottom-up (limited by resources in determining the distribution, activity and abundance of species, and modulating and controlling the productivity [Worm et al., 2003], output, and response of the system). As an example in coral reefs, the process of calcification necessary for the production of reef structures is a probable source of atmospheric $\mathrm{CO}_{2}$ (Kleypas et al., 1999). It is speculated that the impact of increased atmospheric $\mathrm{CO}_{2}$ will be detrimental to these systems. This presumed negative effect stems from recent studies that model future changes in seawater chemistry such as an increase in ocean acidity which would ultimately reduce the calcification rates of corals and other organisms that produce calcium carbonate (Caldeira and Wickett, 2003). However, increased $\mathrm{CO}_{2}$ could also lead to increased photosynthetic activity (Langdon et al., 2003) which could presumably balance out the excess supply of this gas within reef systems.

Evolvability, defined as the capacity to generate heritable phenotypic variation (Kirschner and Gerhart, 1998), may be demonstrated in the form of phenotypic plasticity and variation of corals. Certain species of corals have developed the capacity to alter their morphology and growth in response to changes in the environment. For example, skeletal growth or structure may be modified to become sturdier in response to increased water turbulence or to capture nutrients in a more efficient manner (Kaandorp et al., 1996). This ability may contribute to fitness of these species by ensuring their continued survival, which in turn allows them to pass their genes on to future generations.

\section{RESILIENCE}

Resilience (in contrast to "robustness") is the capacity of a system to self-repair or recover from a disturbance. This usually consists of a return time and is measured as a rate of recovery or change (Pimm, 1991). There are important implications for succession and pathways of development since resilience may be impaired or diminished partially or completely and permanently or temporarily by disturbances. Some of the factors that foster resilience in coral reefs include links such as "legacies" (which are simply leftovers or remnants of past or previous communities), and support areas which act as sources of recruitment (Lundberg and Moberg, 2003). The latter include ecological refuges which can replenish and supply the diversity in a given region. Some researchers thus claim that isolated reefs are less resilient to perturbations such as climate change compared to reefs with higher connectivities (Hughes et al., 2003). At the level of organisms, individual colonies such as Siderastrea radians demonstrate resilience when they recover and regain tissue after losing virtually all of it (Lirman et al., 2002). On a larger scale, studies have been done showing the relatively high probability of coral cover recovery after a disturbance (Connell, 1997). However, there can be great variability and it seems that recovery is quite dependent on the type of disturbance (acute vs. chronic) and the scale (temporal and spatial) of the study.

After a disturbance, new successional pathways become available, allowing chance events and new species composition and interactions to define the equilibrium state (Nyström et al., 2000). The direction of development will depend on which factors that contribute to resilience are present for selforganization (Holling, 2001). Some of the mechanisms involved in or needed for resilience may no longer be present as a consequence of a disturbance (Hughes et al., 2003). This may affect recovery and alter the community that emerges.

In a complex system, recovery may also be characterized by hysteresis. Hysteresis is the asymmetric response of a system to a symmetric reversal of an input variable (Lim and Saloma, 2002). It is a collective and nonlinear type of behaviour observed at different scales, and is dependent on history and requires memory. It could apply to coral reefs that have been subjected to some stress and the subsequent retardation of recovery after that stress is removed (Scheffer et al., 2001). This could pertain to deterioration in water quality and subsequent improvement thereof, or a loss of a keystone species and its later reintroduction.

Another situation where reef processes interact in clear but complex patterns is in PHASE TRANSI- 
TIONS, or changes from one stable state to another (Knowlton, 1992), as when one set of dominant organisms replaces another. In coral reefs, this has been shown in the case of algae replacing corals (Johnson et al., 1995; McClanahan et al., 2002) where waters have been heavily enriched by nutrients, or where algal grazers have been removed by overfishing. The outcomes following disturbances that have significantly altered one or more key processes or factors can be quite unpredictable, nonlinear and novel. However, despite the enormous potential for alternative development pathways, the options are still somewhat constrained and limited by certain fundamental rules. Changes in species dominance, for example, are caused by competition for resources. Different species have different strategies for exploiting these resources. In addition, there is the notion or idea of self-design in which an assemblage of living components will optimize its organization by selecting those parts that together are best adapted to the prevailing environmental conditions (Parrott, 2002). In coral reefs, this may result in a switch from coral-dominated communities to seagrass or algae.

\section{COMMUNITY ASSEMBLY}

After disturbance occurs, the relevant questions usually are: will recovery be possible, and if so, which direction will it most probably take? Does it make sense to assist recovery through active intervention (restoration)? Community responses after disturbance takes place can be viewed as patterns of succession that are driven by key processes and factors. Examples of the latter include competition, dispersal and "legacies", as mentioned above. The progress of a system will accordingly and ultimately depend on the impact of a disturbance on these key processes and factors. Disturbance works to shape a system's "identity" and may release resources (e.g. space or nutrients) that have been trapped, accumulated or locked up in certain areas (Holling, 2001).

Perhaps some of the most clear-cut patterns of reef development at large scales (i.e. the scale of the entire ecosystem) can be discerned in the colonization and recolonization processes that follow perturbations such as storm damage or extensive dynamite blasting. There are several processes involved:

- Recruitment of reef organisms as larvae or propagules or recruitment of fragments of coral, algae and other colonial forms;
- Settlement and post settlement of the recruits;

- Competition among the various organisms for resources as they grow and reproduce;

- Establishment of trophic and other interactions;

- Local dispersal.

The above processes will lead to the establishment of a reef community, either similar to the previous one, or different in varying degrees. As discussed above, a variety of factors will come into play and will interact in determining the resulting pathway of community development.

We suggest that coral reef communities (like all other natural systems) can be viewed as STATISTICAL ensembles of INTERACTING components. In the interest of experimental tractability, these components can easily be taken to be the various functional groups on a reef (from bacteria, to plankton, to the hard corals, naturally, and all the way to the large predators). Each species is to be considered a "complex adaptive system (CAS)" (Brown, 1995). It has an internal environment separated from the external one by a distinct boundary. The community which they form is also a CAS in exactly the same sense. (The terms "complex adaptive systems" and "complex systems" are used interchangeably here. While we make no distinctions between the two, CAS are probably a subset of the more general designation of complex systems.)

The entry of species (frequently as propagules, larvae or juveniles) into available space can be viewed as largely random, governed by, among other things, hydrodynamics, the vagaries of weather, the availability of food and suitable substrate, and the level of competition and predation. Their subsequent settlement and establishment will be determined by a narrower set of factors, most of which relate to their tolerance ranges (to the prevailing environmental conditions), and their prerequisites (biological, chemical, physical) for survival, growth and reproduction.

The various species as complex adaptive systems are, by definition, UNIQUE and INDEPENDENT from each other. In other words, each one has the potential to exist in a different place within a different assemblage or in combination with other species. (There are, of course, a few exceptions such as obligate symbiotic associations.) From the interactions of the species (which, again, are established in a haphazard, if not random, fashion, depending on the order of entry and establishment of species in an area) there arise broad scale, discernible PATTERNS 
(Levin et al., 2001). The mechanisms by which these patterns arise are non-linear and largely unpredictable, by virtue of the thousands of species that inhabit coral reefs in different parts of the world, and the range of unique, local environments which act on them. Yet, they are governed by a few simple "rules" such as the level of primary production, the degree of competition and predation, followed by local dispersal (Kerr et al., 2002), and the action of major environmental factors such as light, temperature, salinity, turbulence, turbidity and nutrient levels.

Coral reef dynamics thus illustrate what complexity scientists would term the emergence of "order" out of complex interactions and processes (Lewin, 1999). Due to this, the patterns that are ultimately detected at large scales can, in fact, be explained in mechanistic terms, as has been done for a very long time, starting with the pioneering work of Odum and Odum (1955) at Enewetak Atoll. The emergence of explainable, sometimes even regular patterns in coral reefs even from different parts of the world (Pandolfi, 2002) is probably a manifestation of "self-organization" (Perry, 1995; Levin 1998). Self-organization can be defined as the generation of spatio-temporal order under nonequilibrium conditions in the absence of any macroscopic description of that order (Parrott, 2002). The complex, non-linear dynamics of community assembly might also help explain why it is impossible to predict adult species composition and distribution from coral settlement patterns alone (literature reviewed in Reyes and Yap, 2001).

\section{THE ISSUE OF HIERARCHY AND SCALE}

Following from the discussion above, a notable feature of complex systems is the emergence of patterns at broad scales despite great heterogeneity and variability at smaller scales. In a comprehensive investigation of Pleistocene reefs in the Caribbean (Pandolfi, 2002), coral communities studied over small spatial and temporal scales (tens of meters, years) show "ecological chaos" because of a disturbance which presumably prevents an equilibrium being attained. However, communities located within tens of kilometres of each other show a "large degree of order." In the words of Done (1999), coral communities, over geologic time, appear to "track their preferred environmental niche." As a result, the same (or similar) coral taxa and growth forms tend to develop in the same geomorphological zones of reefs (Done, 1999). This is despite the huge and largely unpredictable variability at the small scale (as already alluded to in many parts of this paper) in terms of larval dispersal and recruitment, the physiological tolerances of the different species, mode of reproduction, and the types of interactions established. At the community level, these processes are ultimately manifested as indicators in terms of percent coral cover, size frequency distributions, and/or abundance of calcifying versus non-calcifying organisms (Preece and Johnson, 1993; Done, 1999; Murdoch and Aronson, 1999).

Regularities have been shown to emerge at even larger spatial scales. In an investigation of contemporary reefs across the Indian and Pacific Oceans, species of tropical fish and corals were shown to exhibit "highly predictable" patterns of taxonomic composition (Bellwood and Hughes, 2001). The main determinant variable was revealed by principal components analysis to be availability of shallowwater habitat. In other words, this factor constrained the effects of otherwise high variability in dispersal, life history traits, etc. of the species concerned to account for the main regularities in patterns at the biogeographic scale.

In terms of ecosystem function, can the dynamics of coral reefs at larger scales (e.g. the community) be explained or even predicted, given detailed information on processes at small scales (e.g. individual species)? Can these dynamics be resolved through more sophisticated mathematical and computational approaches (Hastings and Palmer, 2003)? Or should such approaches be coupled with more innovative experiments at bigger scales (Carpenter et al., 1995)? If so, how?

At the Marine Science Institute, preliminary attempts have been made to study processes at different scales. Manipulative experiments have been performed to understand the effects of environmental factors such as light (Yap et al., 1995) and water motion (Montebon and Yap, 1995) on isolated coral colonies. These efforts were then scaled up to the natural reef environment, but physiological measurements still made use of incubations of isolated components of a reef community (Yap et al., 1994). An attempt was made to relate the results of these experiments to open water measurements of reef metabolism using Lagrangian flow techniques (Yap et al., 1999). These studies have so far demonstrated similar patterns in the balance of primary production and respiration at different spatial scales. 
The issue of scale is a recurrent problem and remains one of the challenges of ecological modelling. The scale at which a pattern is observed is often much larger than the scale at which the underlying process is studied (Levin, 1992). Knowledge at small scales should consequently and ideally be coupled with patterns at larger scales to address a broader picture (Murdoch and Aronson, 1999). The components affect and are affected by the larger, more complicated systems in which they are embedded. The complexity theory recognizes this and provides a framework in which the relationships between constructs at different hierarchical levels can be accommodated (Parrott, 2002). In addition, the dynamics that complex adaptive systems operate on are universal to the different hierarchical levels of organization. Some common features already mentioned include self-organization, a diversity of components working autonomously, and flows and exchanges of material, information and energy.

\section{FUTURE RESEARCH AND DIRECTIONS}

The appeal that the science of complexity brings to coral reef research is an integrative approach that identifies commonalities with other disciplines ranging from non-linear physics, to natural ecosystem studies, to the social sciences. It offers a powerful tool that can be used to complement, learn from and build on the wealth of knowledge and experiences gained from other fields. However, few challenges remain. Some concepts that can be examined experimentally in the ecological context are those of robustness and resilience. Here, research questions arise such as how to assess the vulnerability of particular sites or areas to a given disturbance and how to evaluate their regenerative capacities. These principles are crucial in assessing the possible fates of coral reefs after a disturbance (whether natural or anthropogenic) such as whether recovery is possible, and what pathways it may take.

With this in mind, it should be evident that the science of complexity should also underpin schemes for habitat restoration (Lockwood and Pimm, 1999). Interventions to "rebuild" natural communities are most likely to succeed if they are able to mimic natural processes of community assembly and organization. It would be interesting to see how the nature of adaptive cycles (Holling, 2001), for example, relates to natural succession in reefs. Changes in reef communities over long time periods for example, may be studied as various stages starting with the growth or exploitation stage, slowly moving towards the conservation or maturation phase, then release or dissolution, and finally reorganization/ renewal. There are very real mechanisms that underlie patterns of succession starting from the colonization of bare space, but they are stochastic, complex and non-linear. The sequences of species arrivals, and the success or failure of establishment of viable interactions among species, are critical determinants of the community that eventually takes shape and becomes established.

Another area that deserves further research is the dynamics of the socio-economic and natural systems which often involve multiple conflicting objectives and interests. The question is how to achieve a solution that satisfies both ecological and socialeconomic needs. Finally, it would be valuable to explore and identify the feedbacks and mechanisms that foster the desired ecological state. This includes seeking viable alternatives that relieve coral reefs from various human pressures and creating environmental conditions that favour their growth and development. Hopefully, the science of complexity can offer a fundamentally new and effective approach to understanding this.

\section{ACKNOWLEDGEMENTS}

This work was greatly helped by fruitful discussions with Dr. Caesar Saloma, Dr. Eduardo Mendoza, Dr. May Lim, Alexander Reyes and Dr. Romeo Dizon. This is contribution no. 346 of the Marine Science Institute, University of the Philippines.

\section{REFERENCES}

Baker, A.C. - 2001. Reef corals bleach to survive change. Nature, 411: 765-66.

Bellwood, D.R. and T.P. Hughes. - 2001. Regional-scale assembly rules and biodiversity of coral reefs. Science, 292: 1532-1534.

Bellwood, D.R., T.P. Hughes, C. Folke and M. Nyström. - 2004. Confronting the coral reef crisis. Nature, 429: 827-833.

Bradbury, R.H. - 1977. Independent lies and holistic truths: towards a theory of coral reef communities as complex systems. Proc. 3rd Int. Coral Reef Symp. Miami, 1: 1-7.

Bradbury, R.H., J.D. van der Laan and D.G. Green. - 1996. The idea of complexity in ecology. Senckenb. Marit., 27: 89 - 96.

Brown, J.H. - 1995. Organisms and species as complex adaptive systems: linking the biology of populations with the physics of ecosystems. In: C.G. Jones and J.H. Lawton (eds.), Linking Species and Ecosystems, pp. 16-24. Chapman and Hall, London. 
Brown, J.H., T.G. Whitham, S.K.M. Ernest and C.A. Gehring. 2001. Complex species interactions and the dynamics of ecological systems: long-term experiments. Science, 293: 643-650.

Buddemeier, R.W. and D.G. Fautin.- 1993. Coral bleaching as an adaptive mechanism. BioScience, 43: 320-326.

Caldeira, K. and M.E. Wickett. - 2003. Anthropogenic carbon and ocean pH. Nature, 425: 365

Carlson, J. M. and J. Doyle. - 2002. Complexity and robustness. Proc. Natl. Acad. Sci. 99: 2538-2545.

Carpenter, S.R., S.W. Chisholm, C.J. Krebs, D.W. Schindler and R.F. Wright. - 1995. Ecosystem experiments. Science, 269: 324-327.

Connell, J. H. - 1997. Disturbance and recovery of coral assemblages. Coral Reefs, 16 (Suppl. S101-S113).

Dent, C.L., G.S. Cumming and S. R. Carpenter. - 2002. Multiple states in river and lake ecosystems. Philos. Trans. R. Soc. Lond., Ser. B, 357: 635-645.

Done, T. J. - 1999. Coral community adaptability to environmental changes at scales of regions, reefs and reef zones. Am. Zool., 39: 66-79.

Haefner, J.W. - 1996. Modeling biological systems: principles and applications. Chapman and Hall, New York.

Hastings, A. and M.A. Palmer. - 2003. A bright future for biologists and mathematicians? Science, 299: 2003-2004.

Hatcher, B.G. - 1984. A maritime accident provides evidence for alternate stable states in benthic communities on coral reefs. Coral Reefs, 3: 199-204.

Hatcher, B.G. - 1997. Coral reef ecosystems: how much greater is the whole than the sum of the parts? Coral Reefs, 16: (Suppl. S77-S91).

Holling, C.S. - 1973. Resilience and stability of ecological systems. Annu. Rev. Ecol. Syst. 4: 1-23.

Holling, C.S. - 1996. Engineering resilience versus ecological resilience. In: P.C. Schulze (ed.), Engineering within Ecological Constraints, pp. 31-43. National Academy Press, Washington D.C.

Holling, C.S. - 2001. Understanding the complexity of economic, ecological, and social systems. Ecosystems, 4: 390-405.

Hughes, T. P., A. H. Baird, D. R. Bellwood, M. Card, S. R. Connolly, C. Folke, R. Grosberg, O. Hoegh-Guldberg, J. B. C. Jackson, J. Kleypas, J. M. Lough, P. Marshall, M. Nyström, S. R. Palumbi, J. M. Pandolfi, B. Rosen and J. Roughgarden. 2003. Climate change, human impacts, and the resilience of coral reefs. Science, 301: 929-933.

Jen, E. - 2001. Stable or robust? What's the difference? [RS-2001024] Santa Fe Institute, http://discuss.santafe.edu/robustness/ stories/StoryReader $\$ 24$

Johnson, C., D. Klumpp, J. Field and R. Bradbury - 1995. Carbon flux on coral reefs: effects of large shifts in community structure. Mar. Ecol. Progr. Ser. 126: 123-143.

Kaandorp, J.A., C.P. Lowe, D. Frenkel and P.M.A. Sloot. - 1996. Effect of nutrient diffusion and flow on coral morphology. Phys. Rev. Lett., 77: 2328-2331.

Kerr, B., M.A. Riley, M.W. Feldman and B.J.M. Bohannan. -2002. Local dispersal promotes biodiversity in a real-life game of rock-paper-scissors. Nature, 418: 171-174.

Kirschner, M. and J. Gerhart. - 1998. Evolvability. Proc. Natl. Acad. Sci., 95: 8420-8427.

Kitano, H. - 2001. Foundations of systems biology. MIT Press, Cambridge/MA

Kleypas, J.A., R.W. Buddemeier, D. Archer, J.-P. Gattuso, C. Langdon and B.N. Opdyke. - 1999. Geochemical consequences of increased atmospheric $\mathrm{CO}_{2}$ on coral reefs. Science, 284: $118-120$.

Knowlton, N. - 1992. Thresholds and multiple stable states in coral reef community dynamics. Am. Zool., 32: 674-682.

Langdon, C., W.S. Broecker, D.E. Hammond, E. Glenn, K. Fitzsimmons, S.G. Nelson, T.-S. Peng, I. Hajdas and G. Bonani. - 2003. Effect of elevated $\mathrm{CO}_{2}$ on the community metabolism of an experimental coral reef. Global Biogeochem. Cy. 17: 10.1029/2002GB001941.

Levin, S.A. - 1992. The problem of pattern and scale in ecology. Ecology, 73: 1943-1967.

Levin, S.A. - 1998. Ecosystems and the biosphere as complex adaptive systems. Ecosystems, 1: 431-436.

Levin, S.A., J. Dushoff and J.E. Keymer. - 2001. Community assembly and the emergence of ecosystem pattern. Sci. Mar., 65 (Suppl. 2): 171-179.

Lewin, R. - 1999. Complexity: life at the edge of chaos. 2nd ed. Univ. of Chicago Press, Chicago.

Lim, M. and C. Saloma. - 2002. Emergence of hysteresis in a network of nonhysteretic agents with continuous responses. Phys. Rev. Lett., 88: 038701-1-4.

Lirman D., D. Manzello and S. Maciá. - 2002. Back from the dead the resilience of Siderastrea radians to severe stress. Coral Reefs, 21: 291-292.

Lockwood, J.L. and S.L. Pimm. - 1999. When does restoration succeed? In: E. Weiher and P. Keddy (eds.), Ecological Assembly Rules: Perspectives, Advances, Retreats, pp. 363-392. Cambridge Univ. Press, New York.

Lundberg, J. and F. Moberg. - 2003. Mobile link organisms and ecosystem functioning: implications for ecosystem resilience management. Ecosystems, 6: 87-98.

May, R.M. - 1977. Thresholds and breakpoints in ecosystems with a multiplicity of stable states. Nature, 269: 471-477.

McClanahan, T., N. Polunin and T. Done. - 2002. Ecological states and the resilience of coral reefs, http://www.consecol.org/ vol6/iss $2 /$ art18.

Montebon, A.R.F. and H.T. Yap. - 1995. Metabolic responses of the scleractinian coral Porites cylindrica Dana to water motion. I. Oxygen flux studies. J. Exp. Mar. Biol. Ecol., 186: 33-52.

Murdoch, T.J.T. and R.B. Aronson. - 1999. Scale-dependent spatial variability of coral assemblages along the Florida reef tract. Coral Reefs, 18: 341-351.

Nyström, M., C. Folke and F. Moberg. - 2000. Coral reef disturbance and resilience in a human dominated environment. Trends Ecol. Evol., 15: 413-417.

Odum, H.T. and E.P. Odum. - 1955. Trophic structure and productivity of a windward coral reef community on Eniwetok Atoll. Ecol. Monogr., 25: 381-410.

O'Neill, R.V., D.L. DeAngelis, J.B. Waide and T.F.H. Allen. 1986. A hierarchical concept of ecosystems. Princeton Univ. Press, New Jersey.

Pandolfi, J.M. - 2002. Coral community dynamics at multiple scales. Coral Reefs, 21: 13-23.

Parrott, L. - 2002. Complexity and the limits of ecological engineering. Trans Am. Soc. Agric. Eng., 45: 1697-1702.

Perry, D.A. - 1995. Self-organizing systems across scales. Trends Ecol. Evol., 10: 241-244.

Peterson, G., C.R. Allen and C.S. Holling. - 1998. Ecological resilience, biodiversity, and scale. Ecosystems, 1: 6-18.

Pimm, S. L. - 1991. The balance of nature? The Univ. of Chicago Press, Chicago

Preece, A.L. and C.R. Johnson. - 1993. Recovery of model coral communities: complex behaviours from interaction of parameters operating at different spatial scales. In: D.G. Green and T. Bossomaier (eds.), Complex Systems: From Biology to Computation, pp. 69-81. IOS Press, Amsterdam.

Reyes, M.Z. and H.T. Yap. - 2001. Effect of artificial substratum material and resident adults on coral settlement patterns at Danjugan Island, Philippines. Bull. Mar. Sci., 69: 559-566.

Scheffer, M., S. Carpenter, J.A. Foley, C. Folke and B. Walker. 2001. Catastrophic shifts in ecosystems. Nature, 413: 591-596.

Solé, R.V., R.F. Cancho, J.M. Montoya and S. Valverde. - 2003. Selection, tinkering and emergence in complex networks. Complexity, 8: 20-33.

Worm, B. and J.E. Duffy. - 2003. Biodiversity, productivity and stability in real food webs. Trends Ecol. Evol., 18: 628-632.

Yap, H.T., R.M. Dizon and A.R.F. Montebon. - 1999. Metabolism of a northwestern Philippine coral reef flat measured at two spatial scales. Philipp. J. Sci., 128: 211-223.

Yap, H.T., A.R.F. Montebon and R.M. Dizon. - 1994. Energy flow and seasonality in a tropical coral reef flat. Mar. Ecol. Progr. Ser., 103: 35-43.

Yap, H.T., A.R.F. Montebon, J.-A. von Oertzen and R.M. Dizon. 1995. Experimental manipulations of a solitary coral (Fungia, Scleractinia) with emphasis on the effects of light. Bull. Mar. Sci., 56: 319-329.

Scient. ed.: P.J. Wangersky

Received June 13, 2005. Accepted December 23, 2005. 